\title{
Left ventricular function and survival in ischemic cardiomyopathy: Implications for surgical ventricular restoration
}

Srilakshmi M. Adhyapak, DNB, ${ }^{\mathrm{a}}$ V. Rao Parachuri, FRCS(CTh), ${ }^{\mathrm{b}}$ Tinku Thomas, PhD,${ }^{\mathrm{c}}$ and Kiron Varghese, MD, $\mathrm{DM}^{\mathrm{a}}$

\section{ABSTRACT}

Objectives: This pilot study evaluates the association of relative wall thickness (RWT) on survival in patients with ischemic cardiomyopathy (ICM). We hypothesized that patients with preserved RWT may be better candidates for surgical ventricular restoration than those with thinner RWT.

Methods: Echocardiography was performed in 165 consecutive patients (aged $58.2 \pm 14.7$ years) divided into 2 groups based on RWT values. Group 1 had patients with preserved RWT and group 2 had patients with reduced RWT.

Results: There were $120(72.7 \%)$ patients with hypertension and $112(67.8 \%)$ patients had diabetes mellitus. The patients with preserved RWT (group 1) had significantly more hypertension and diabetes. The patients with decreased RWT (group 2) were in a higher New York Heart Association functional class and had significantly greater incidence of anterior wall myocardial infarction. The entire cohort was followed over 24 months (group 1: $n=117$ and group $2: n=48$ ). The overall all-cause mortality in group 1 (preserved RWT) was $7(5.9 \%)$ and in group 2 (reduced RWT) was $35(72.9 \%)(P<.0001)$. When readmission for congestive heart failure was analyzed, group 2 patients with lower RWT $(P<.0001)$ had an increased rate of readmissions for heart failure.

Conclusions: In patients with ischemic cardiomyopathy, a lower RWT indicative of dilated LV remodeling was associated with increased mortality and readmission for heart failure. The RWT may be a simple benchmark of viable or contractile myocardium in ICM. It can be hypothesized that patients with preserved RWT may benefit from surgical ventricular restoration. (JTCVS Open 2021;7:211-8)

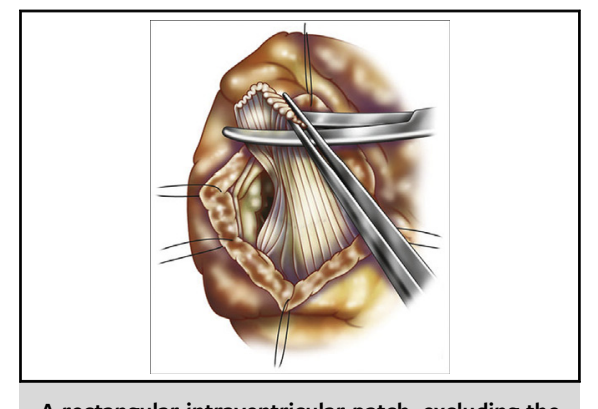

A rectangular intraventricular patch, excluding the left ventricular aneurysm during SVR.

CENTRAL MESSAGE

Preserved relative wall thickness

was associated with reduced

mortality at 24 months in pa-

tients with ICM receiving medical

therapy, leading to a hypothesis

that it may define responders to

SVR.

\section{PERSPECTIVE}

In patients with systolic HF, an independent and incremental risk of adverse outcome was associated with increased mass index and decreased RWT. We found that in patients with ICM, preserved RWT was associated with lesser mortality than those with lower RWT. Baseline preserved RWT can be a simple benchmark of viable myocardium, making it an indicator of success for SVR.

See Commentaries on pages 219 and 221.

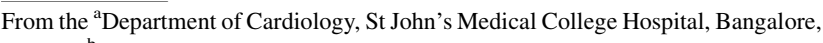
India; ${ }^{\mathrm{b}}$ Narayana Hrudayalaya Institute of Medical Sciences, Bangalore, India; and ${ }^{\mathrm{c}}$ Department of Biostatistics, St John's Research Institute, Bangalore, India. Received for publication Feb 28, 2021; accepted for publication March 1, 2021; available ahead of print March 28, 2021.

Address for reprints: Srilakshmi M. Adhyapak, DNB, Department of Cardiology, St John's Medical College Hospital, Bangalore 560034, India (E-mail: srili2881967@yahoo.com).

2666-2736

Copyright (C) 2021 The American Association for Thoracic Surgery. Published by Elsevier Inc. on behalf of The American Association for Thoracic Surgery. Published by Elsevier Inc. This is an open access article under the CC BY-NC-ND license (http://creativecommons.org/licenses/by-nc-nd/4.0/).

https://doi.org/10.1016/j.xjon.2021.03.001
}

$\checkmark$ Video clip is available online.

The Surgical Treatment for Ischemic Heart Failure (STICH) trial caused a decline in the practice of surgical ventricular restoration (SVR) for advanced heart failure in patients with ischemic cardiomyopathy (ICM). ${ }^{1}$ Although the STICH trial has been criticized by several authors, primarily for its conduct and methodology, SVR has been demonstrated to have efficacy in certain populations with 


\section{Abbreviations and Acronyms \\ $\mathrm{CABG}=$ coronary artery bypass grafting \\ E/A ratio = early mitral filling velocity/late filling velocity
ESVI = end systolic volume index
ICM = ischemic cardiomyopathy
$\mathrm{LV} \quad=$ left ventricle
LVEF $\quad=$ left ventricular ejection fraction \\ MI $\quad=$ myocardial infarction \\ $\mathrm{NT}$ pro-BNP $=\mathrm{N}$-terminal pro B-type natriuretic peptide
NYHA $=$ New York Heart Association
RFP $\quad=$ restrictive filling pattern
RWT $=$ relative wall thickness Heart Failure
SVR = surgical ventricular restoration
TDI $=$ tissue Doppler index \\ STITCH = Surgical Treatment for Ischemic}

refractory heart failure. ${ }^{2,3}$ Stringent inclusion criteria are required for the success of SVR, chief of which is presence of a contractile remote myocardium in a preoperative left ventricle (LV).

In patients with ICM receiving medical management, it was found that patients with preserved relative wall thickness (RWT) had better survival than patients with reduced RWT. $^{4}$ Those patients with more adverse LV remodeling had worse LV systolic and diastolic dysfunction.

An LV restrictive filling pattern (RFP) is an index of severe diastolic dysfunction in patients with ICM. ${ }^{5,6}$ Several studies have shown RFP to be a strong predictor of LV remodeling and adverse clinical outcome, independent of age and LV ejection fraction (LVEF). ${ }^{6}$ In patients who undergo SVR, the RFP reversed to normal in patients with preserved RWT. ${ }^{7}$ Therefore, we designed this pilot study to study the association of preserved RWT on LV function and survival in patients with ICM receiving medical therapy. We hypothesized that this would help define responders to SVR.

\section{METHODS}

This was a prospective study conducted in the Department of Cardiology at St John's Medical College Hospital, Bangalore, India, from December 2017 to January 2020. We enrolled 165 patients who presented to our department with congestive heart failure. All patients had a history of ST elevation/non-ST elevation myocardial infarction. The exclusion criteria were atrial fibrillation or other persistent cardiac rhythm alterations, ventricular paced rhythm, left bundle branch block, any mitral or aortic valve stenosis, previous valve repair or prosthetic valve implant, moderate-to-severe mitral regurgitation, need for valve surgery, cardiogenic shock or LV assist devices, and suboptimal echocardiographic examination. All patients underwent routine blood investigations and a baseline N-terminal pro B-type natriuretic peptide (NT pro-BNP). All patients were followed-up clinically until the end of study ( 24 months). All-cause mortality and readmissions for heart failure were analyzed.
The study was approved by our institutional ethics committee (IEC Ref No. 22/2017 dated March 10,2017) and all patients gave informed consent for being part of the study and for serial 2-dimensional echocardiograms and possible publication of data with ensured patient confidentiality.

\section{Echocardiographic Study}

Echocardiographic examination was done at baseline and at 6, 12, 18, and 24 months using a GE Vivid 7 machine (GE Healthcare, Chicago, Ill). We registered the averages of measurements of 3 cardiac cycles for each patient with echocardiographic monitoring. A standard 2dimensional echocardiographic study was performed for assessment of LV wall thickness and dimensions according to the American Society of Echocardiography/European Association of Echocardiography recommendations. ${ }^{8}$ Diastolic and systolic LV internal diameters were measured from the parasternal long-axis view. Septal wall thickness and posterior wall thickness were measured in end-diastole. The RWT was calculated as $2 \times$ posterior wall thickness/LV diastolic diameter. EF was measured by Simpson's method. ${ }^{9}$ Systolic pulmonary artery pressure was calculated from the tricuspid regurgitation trace using continuous wave Doppler. ${ }^{9}$ The entire sample was classified into 2 groups based on RWT (RWT $\geq 0.34$ and RWT $<0.34$ ).

\section{Diastolic Parameters}

Measures of the ratio of early mitral filling velocity/late filling velocity (E/A ratio), and E-velocity deceleration time were done on the pulsed-wave Doppler mitral-inflow profile. ${ }^{4}$ Tissue Doppler imaging was done by placing the sample volume at the side of the medial (septal $\mathrm{e}^{\prime}$ ) and lateral annulus (lateral $\mathrm{e}^{\prime}$ )from the apical 4-chamber view. ${ }^{8}$ Diastolic filling pattern was defined as restrictive with $\mathrm{E} / \mathrm{A}$ ratio $\geq 2$.

\section{Statistical Analysis}

Categorical variables are presented as counts and percentages and compared using the $\chi^{2}$ test. The distribution of all continuous echocardiographic variables were examined using QQ plots and summarized as mean and standard deviation and compared between groups by independent samples $t$ test. Survival time and time to readmission were compared between the RWT groups using Kaplan-Meir plots with $95 \%$ confidence interval and Log-rank test.

The echocardiographic measures were compared between baseline, 6 , 12,18 , and 24 months follow-up times using repeated measures analysis of variance. A $P$ value $<.05$ was considered statistically significant. All analyses were carried out using STATA release 15 (StataCorp, College Station, Tex).

\section{RESULTS}

\section{Patient Population}

There were 118 men and the mean age of the study population was $58.28 \pm 14.7$ years. All patients had experienced a prior myocardial infarction (MI) (median time lapse from MI to present admission was 7.5 months). A majority had experienced an anterior wall MI $(n=84)$, whereas 7 patients experienced inferior wall MI. The remaining 74 patients experienced non-ST elevation MI. A majority were classified as having advanced stage heart disease (New York Heart Association [NYHA] functional class III or IV in $70 \%$ of cases). All patients were receiving maximally tolerated doses of antifailure medications, which included angiotensin converting enzyme inhibitors, angiotensin receptor inhibitors, loop diuretics, spironolactone, cardioselective beta blockers, dual antiplatelet agent, and 
statins; some patients were taking digoxin and those eligible were taking sacubitril. There were $120(72.7 \%)$ patients with hypertension and $112(67.8 \%)$ patients had diabetes mellitus. The baseline clinical parameters are listed in Table 1. The patients with preserved RWT (group 1; $\mathrm{n}=117$ ) had significantly more hypertension and diabetes. The patients with decreased RWT (group 2; $\mathrm{n}=48$ ) were in a significantly higher NYHA functional class and had significantly greater incidence of anterior wall MI (Table 1). The overall all-cause mortality in group 1 was $7(5.9 \%)$ and in group 2 was $35(72.9 \%)(P<.0001)$ (Figures 1 and 2$)$. The NT pro-BNP at baseline was more significantly elevated in group 2 compared with group 1 (1200.5 \pm 400 vs $2500.7 \pm 346 ; P<.0001)$.

All patients were followed on an outpatient basis. The number of readmissions for heart failure in group 1 was 31 $(26.5 \%)$ and in group 2 was $58(120.8 \%)(P<.0001)$. Information on patients who did not come for follow-up was procured by telephone for clinical update (death and/or hospitalizations). None of the patients underwent SVR, LV assist device, or heart transplant.

\section{Echocardiographic Data}

All patients showed an echocardiographic picture of typical ICM with severely reduced LVEF, increased LV end diastolic volume index, increased left atrial volume, high systolic pulmonary artery pressure $(>40 \mathrm{~mm} \mathrm{Hg})$. They were divided into 2 groups based on RWT (Table 2). The left atrial volume was also higher in group 2. Severe LV diastolic dysfunction as defined by $\mathrm{E} / \mathrm{A}$ and $\mathrm{E} / \mathrm{e}^{\prime}$ was also higher in group 2. Out of 165 patients studied who fulfilled all inclusion criteria, 30 patients had RFP defined as E/A $\geq 2$.

When the entire cohort was analyzed, it was seen that patients with greater LV internal diameter end diastole $(P<.0001)$, greater LV internal diameter end systole $(P=.0009)$, greater left atrial volume $(P=.02)$, RFP: E/ A $>2(P=.02)$ had lesser RWT $(P<.0001)$. Patients

TABLE 1. Baseline clinical characteristics of patients

\begin{tabular}{lccc}
\hline $\begin{array}{c}\text { Clinical } \\
\text { characteristic }\end{array}$ & $\begin{array}{c}\text { RWT }>\mathbf{0 . 3 4} \\
(\mathbf{n}=\mathbf{1 1 7})\end{array}$ & $\begin{array}{c}\text { RWT }<\mathbf{0 . 3 4} \\
(\mathbf{n}=\mathbf{4 8})\end{array}$ & $\boldsymbol{P}$ value \\
\hline Age & $62 \pm 14.2$ & $58.8 \pm 6.8$ & .736 \\
Male & $98(84)$ & $20(42)$ & .184 \\
\hline Htn & $101(86)$ & $19(40)$ & $<.001$ \\
DM & $89(76)$ & $23(48)$ & .008 \\
\hline AWMI & $45(38)$ & $39(81)$ & $<.001$ \\
IWMI & $6(5)$ & $1(2 \%)$ & .675 \\
\hline NSTEMI & $52(44)$ & $22(46)$ & .999 \\
NYHA & & $3.85 \pm 2.1$ & .0086 \\
\multicolumn{1}{c}{ functional class } & $2.98 \pm 1.12$ & & \\
\hline
\end{tabular}

Values are presented as mean \pm standard deviation or $\mathrm{n}(\%) . R W T$, Relative wall thickness; Htn, hypertension; $D M$, diabetes mellitus; $A W M I$, anterior wall myocardial infarction; IWMI, inferior wall myocardial infarction; NSTEMI, non-ST elevation myocardial infarction; NYHA, New York Heart Association. with ICM who presented with congestive heart failure, those who had thinner LV walls demonstrated by lower RWT (group 2) had increased mortality (median survival, 17 months; $P<.0001$ ) (Figure 1). These patients had a baseline geometric pattern of LV dilated remodeling, indicated by very low RWT and associated very high NT pro-BNP levels. The patients with preserved RWT (group 1) demonstrated a baseline eccentric remodeling and had lower mortality with associated lower NT pro-BNP levels. In our cohort, the RFP had no association with mortality The RFP did not correlate with RWT. The association of RFP could again be confounded by the small sample size of patients with RFP.

\section{Follow-up Echocardiographic Data}

The echocardiographic measures demonstrated LV dilatation, which was significant over time at $6,12,18$, and 24 months in both groups (Table 3). There was further LV dilatation noted at follow-up, although the increase in LV dimensions was not significant. The diastolic dysfunction as measured by the E/A ratio remained almost the same in group 1 with preserved RWT, whereas in group 2 with decreased RWT it showed improvement at 24 months (Figure 3).

\section{DISCUSSION}

In a study of systolic heart failure, it was shown that eccentric LV remodeling defined as preserved RWT and patients with thinner LV posterior walls (lower RWT) had a relatively more dilated pattern of remodeling similar to dilated cardiomyopathy, when followed-up, had an independent and incremental risk of adverse outcome associated with decreased RWT.

In our patients with ICM and systolic heart failure, patients with decreased RWT were in more advanced heart failure as assessed by NYHA functional class. These patients had significantly greater LV diameters and significantly lesser LVEF, demonstrating significantly greater systolic dysfunction than the patients with preserved RWT. This was also reflected by a greater level of baseline NT pro-BNP. The E/A ratio was greater in the patients with decreased RWT signifying greater diastolic dysfunction. The left atrial dimensions were also significantly greater, as was the deceleration time, which are indirect indicators of diastolic dysfunction. ${ }^{7}$ When followed over 24 months, there was a significantly higher all-cause mortality and significantly greater readmissions for heart failure in patients with decreased RWT. Elevated levels of BNP are strongly associated with outcomes, independent of therapy. ${ }^{10,11}$ At 24 months of follow-up, there was an increase in LV dimensions in both groups, although not statistically significant (Table 3). But, the LV dimensions of group 2 remained significantly larger than group 1 . The LVEF was also similarly lesser in group 2 at 24 months but was not significantly different from its baseline values. The diastolic 


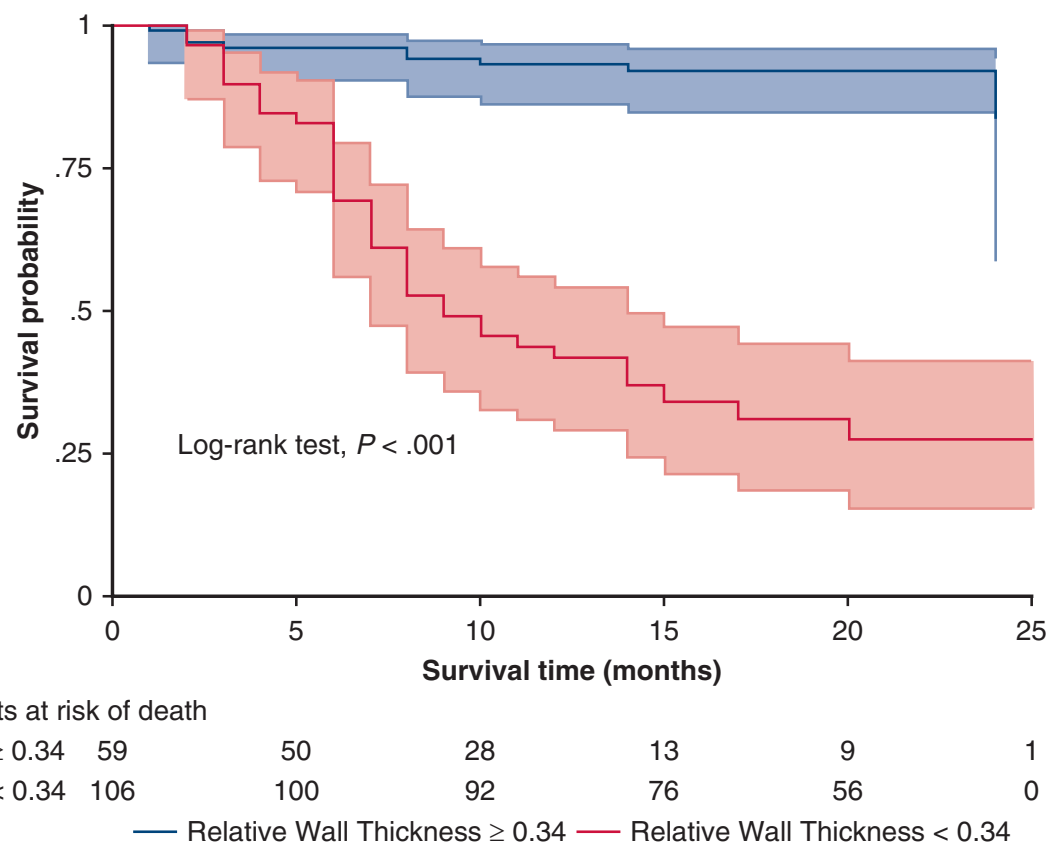

FIGURE 1. Kaplan-Meier survival plot of mortality for congestive heart failure. Two lines represent relative wall thickness $(R W T) \geq 0.34$ and RWT $<0.34$ groups. Shaded area represents the $95 \%$ confidence interval. The numbers at risk at the beginning of the follow-up time were $\mathrm{n}=106$ in RWT $\geq 0.34$ group and $\mathrm{n}=59$ in RWT $<0.34$ group. Mortality was 9 and 39 in the 2 groups, respectively. Log-rank test $P<.001$ for the comparison between the 2 RWT groups.

function as measured by the E/A ratio did not vary at 24 months from baseline in group 1 and showed improvements in group 2 at 12 months onward. We had only 30 patients with RFP $(\mathrm{E} / \mathrm{A}>2)$. Because this sample size was small, we were not able to define the effect of RFP and diastolic dysfunction on clinical outcomes.

All of these patients, while on maximally tolerated antiheart failure medications, had significantly higher all-cause

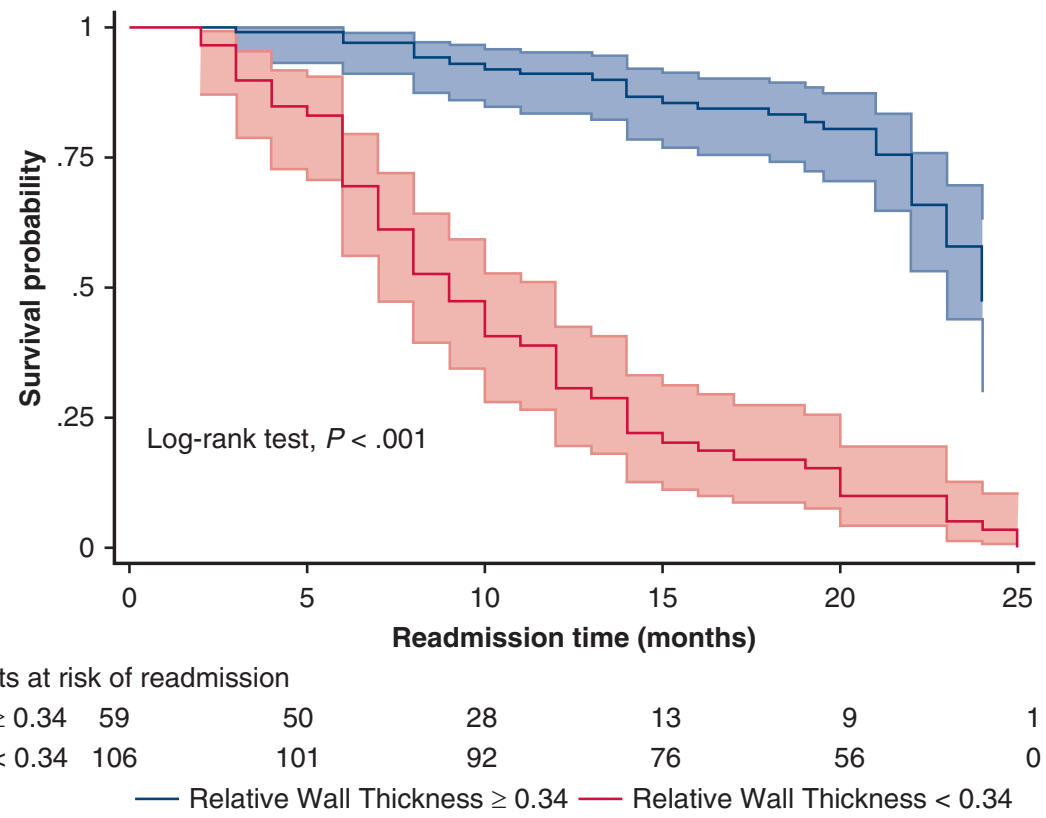

FIGURE 2. Kaplan-Meier plot of readmission during the follow-up period. Two lines represent relative wall thickness $(R W T) \geq 0.34$ and RWT $<0.34$ groups. Shaded area represents the $95 \%$ confidence interval. The numbers at risk at the beginning of the follow-up time were $\mathrm{n}=106$ in RWT $\geq 0.34$ group and $\mathrm{n}=59$ in RWT $<0.34$ group. Readmissions were 31 and 58 in the 2 groups, respectively. Log-rank test $P<.001$ for the comparison between the 2 RWT groups. 
TABLE 2. Two-dimensional (2D) echocardiographic parameters of the 4 groups of ischemic cardiomyopathy patients

\begin{tabular}{|c|c|c|c|}
\hline 2D study & $\begin{array}{c}\mathbf{R W T} \geq 0.34 \\
(\mathbf{n}=117)\end{array}$ & $\begin{array}{c}\mathbf{R W T}<0.34 \\
(\mathrm{n}=\mathbf{4 8})\end{array}$ & $\begin{array}{l}\text { Intergroups } \\
\text { comparison }\end{array}$ \\
\hline LVIDd (cms) & $4.96 \pm 0.67$ & $5.72 \pm 0.67$ & $<.0001$ \\
\hline LVIDs (cms) & $3.66 \pm 0.72$ & $4.40 \pm 0.86$ & $<.0001$ \\
\hline LVEF (\%) & $38.37 \pm 6.03$ & $35.27 \pm 7.39$ & $<.0001$ \\
\hline PASP $(\mathrm{mm} \mathrm{Hg})$ & $35.42 \pm 12.80$ & $35.22 \pm 11.27$ & $<.0001$ \\
\hline $\mathrm{LA}(\mathrm{cms})$ & $3.82 \pm 0.72$ & $3.90 \pm 0.53$ & .0025 \\
\hline E/A ratio & $0.96 \pm 0.41$ & $1.01 \pm 0.39$ & .0005 \\
\hline $\mathrm{E} / \mathrm{e}^{\prime}$ ratio & $11.19 \pm 3.80$ & $12.13 \pm 5.39$ & .003 \\
\hline DT (msec) & $152.44 \pm 46.15$ & $159.02 \pm 54.53$ & .014 \\
\hline PWDd (cms) & $1.088 \pm 0.14$ & $0.95 \pm 0.18$ & $<.0001$ \\
\hline IVSd (cms) & $1.068 \pm 0.20$ & $0.92 \pm 0.20$ & .0002 \\
\hline RWT (cms) & $0.43 \pm 0.07$ & $0.32 \pm 0.089$ & $<.0001$ \\
\hline TAPSE & $1.96 \pm 0.298$ & $1.89 \pm 0.34$ & .02 \\
\hline
\end{tabular}

$R W T$, Relative wall thickness; $L V I D s$, left ventricular diameter in diastole; $L V I D s$, left ventricular diameter in systole; $L V E F$, left ventricular ejection fraction; $P A S P$, systolic pulmonary artery pressure; $L A$, left atrial; $E / A$, early mitral filling to late mitral filling velocity; $E / e^{\prime}$, TDI e wave velocity; $D T$, deceleration time; $P W D d$, posterior wall diameter in diastole; $I V S d$, interventricular septal diameter in diastole; $R F P$, restrictive filling pattern; TAPSE, tricuspid annular motion in systole.

mortality and readmissions for heart failure. SVR has shown benefit in patients with ICM and refractory heart failure. ${ }^{3}$ The LV volume tends to be only a weak determinant of clinical improvement because it has often been observed that patients with the same end diastolic volume, end systolic volume, and EF have diverging prognosis. ${ }^{12,13}$ For the success of SVR, a discrete area of dyskinesis/akinesis with preserved contractile remote myocardium is a prerequisite.

The main focus should be directed toward the nature of myocardial tissue that is left behind after scar excision during SVR (Video 1). The nature of the border zone myocardium and viability of the contractile myocardium needs to be ascertained before SVR.

Analyzing survival based on the preoperative LV substrate in the largest registry on SVR the overall 5-year survival was $69 \%$. $^{3}$ In the subanalysis based on whether the area of infarct was akinetic or dyskinetic, the overall 5-year survival for dyskinesia was $80 \%$, whereas for akinesia it was $65 \%$. Although akinesia was present in $66 \%$ of cases, dyskinesia was seen in $34 \%$. Among the ventricles with LVend-systolic volume index (ESVI) $\geq 80 \mathrm{~mL} / \mathrm{m}^{2}$, akinesia was present in $73.3 \%$ and dyskinesia in $26.7 \%$. When survival was analyzed based on the preoperative end-systolic volume index signifying LV dilatation, the patients with ESVI $<80 \mathrm{~mL} / \mathrm{m}^{2}$ had a 5 -year survival of $80 \%$, whereas patients with ESVI of 80 to $120 \mathrm{~mL} / \mathrm{m}^{2}$ had a 5-year survival of $70 \%$. The patients with ESVI $\geq 120 \mathrm{~mL} / \mathrm{m}^{2}$ had the lowest 5 -year survival at $64 \%$. These findings lead us to infer that SVR in larger ventricles associated with an akinetic scar have a relatively worse prognosis than smaller ventricles with predominantly dyskinetic scars. However, earlier studies by Di Donato and colleagues ${ }^{13}$ have demonstrated that patients with a large akinetic LV aneurysm who had the most severely impaired preoperative cardiac function (largest ventricular volumes and highest mean pulmonary pressures) benefited from aneurysm repair as much as those with dyskinetic aneurysm.

The eccentric LV remodeling with preserved RWT was shown to be beneficial following SVR. ${ }^{7}$ There were significant improvements in the RFP following SVR only in those patients with preserved RWT at baseline. The preservation of RWT can be considered a marker for contractile reserve in patients with $\mathrm{LV}$ aneurysms.

Although the clinical benefits of SVR have been demonstrated in large registries, the STICH trial negated the

TABLE 3. Two-dimensional echocardiographic parameters of the 2 groups of ischemic cardiomyopathy patients at follow-up

\begin{tabular}{|c|c|c|c|c|c|c|}
\hline Parameter & Group & $\begin{array}{c}6 \mathrm{mo} \\
(\mathrm{n}=141)\end{array}$ & $\begin{array}{c}12 \mathrm{mo} \\
(\mathrm{n}=123)\end{array}$ & $\begin{array}{c}18 \mathrm{mo} \\
(\mathrm{n}=118)\end{array}$ & $\begin{array}{c}24 \mathrm{mo} \\
(\mathrm{n}=117)\end{array}$ & $\begin{array}{c}\text { Time } \times \text { group } \\
\text { interaction } P \text { value } *\end{array}$ \\
\hline \multirow[t]{2}{*}{ LVIDd (cms) } & $\mathrm{RWT} \geq 0.34$ & $4.96 \pm 0.67$ & $5.72 \pm 0.67$ & $5.34 \pm 0.6$ & $5.37 \pm 0.59$ & .132 \\
\hline & RWT $<0.34$ & $5.92 \pm 0.94$ & $6.18 \pm 0.67$ & $6.0 \pm 0.67$ & $6.11 \pm 0.7$ & \\
\hline \multirow[t]{2}{*}{ LVIDs (cms) } & $\mathrm{RWT} \geq 0.34$ & $3.66 \pm 0.72$ & $4.40 \pm 0.86$ & $3.97 \pm 0.69$ & $3.97 \pm 0.69$ & .990 \\
\hline & RWT $<0.34$ & $4.74 \pm 0.83$ & $4.98 \pm 0.69$ & $4.92 \pm 0.68$ & $4.9 \pm 0.7$ & \\
\hline \multirow[t]{2}{*}{$\operatorname{LVEF}(\%)$} & RWT $\geq 0.34$ & $38.37 \pm 6.03$ & $35.27 \pm 7.39$ & $36.1 \pm 6.1$ & $36.6 \pm 6.09$ & .836 \\
\hline & RWT < 0.34 & $31.45 \pm 7.53$ & $31 \pm 7.5$ & $31.4 \pm 7.9$ & $31.4 \pm 8.33$ & \\
\hline \multirow[t]{2}{*}{ LA (cms) } & $\mathrm{RWT} \geq 0.34$ & $3.84 \pm 0.7$ & $4.17 \pm 3.4$ & $3.87 \pm 0.62$ & $3.87 \pm 0.62$ & .921 \\
\hline & $\mathrm{RWT}<0.34$ & $3.82 \pm 0.72$ & $3.90 \pm 0.53$ & $3.98 \pm 0.42$ & $3.98 \pm 0.44$ & \\
\hline \multirow[t]{2}{*}{ E/A ratio } & $\mathrm{RWT} \geq 0.34$ & $0.96 \pm 0.41$ & $1.01 \pm 0.39$ & $1.19 \pm 0.63$ & $1.19 \pm 0.63$ & $<.001$ \\
\hline & RWT $<0.34$ & $1.19 \pm 3.80$ & $1.13 \pm 5.39$ & $1.24 \pm 0.87$ & $1.26 \pm 0.88$ & \\
\hline \multirow[t]{2}{*}{ RWT (cms) } & $\mathrm{RWT} \geq 0.34$ & $0.43 \pm 0.07$ & $0.42 \pm 0.008$ & $0.42 \pm 0.08$ & $0.42 \pm 0.08$ & .9951 \\
\hline & RWT $<0.34$ & $0.27 \pm 0.072$ & $0.28 \pm 0.011$ & $0.29 \pm 0.05$ & $0.28 \pm 0.06$ & \\
\hline
\end{tabular}

Values are presented as mean \pm standard deviation. $L V I D d$, Left ventricular diameter in diastole; $R W T$, relative wall thickness; $L V I D s$, left ventricular diameter in systole; $L V E F$, left ventricular ejection fraction; $L A$, left atrial; $E / A$ ratio, early mitral filling to late mitral filling velocity. ${ }^{*} P$ value from repeated measures analysis of variance. 


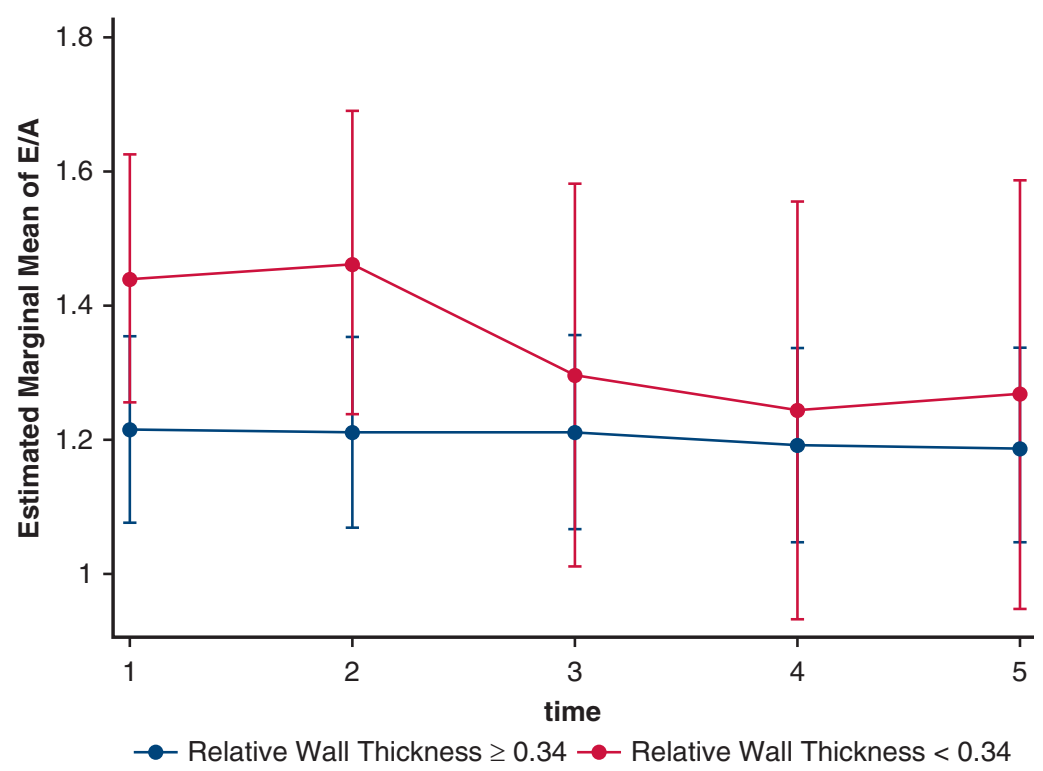

FIGURE 3. Estimated average ratio of the early mitral filling velocity/late filling velocity $(E / A)$ and $95 \%$ confidence interval at each follow-up time in the relative wall thickness $($ RWT $) \geq 0.34$ and $\mathrm{RWT}<0.34$ groups.

beneficial effects of SVR when performed concomitantly with coronary artery bypass grafting (CABG). ${ }^{1}$ There were several problems with the conduct of this study; $13 \%$ of patients enrolled in the STICH trial had no MI. Myocardial viability was investigated only in 267 patients $(26.7 \%)$, among whom non-viable myocardium was present in 76 patients only $(28.5 \%)$. Out of the 191 patients with viable myocardium, 99 underwent CABG plus SVR and $92 \%$ underwent CABG alone. Then, extrapolating the data, $37.1 \%$ (99 out of 237) of all patients had an inappropriate procedure. ${ }^{14}$ It is known that patients who had, during the

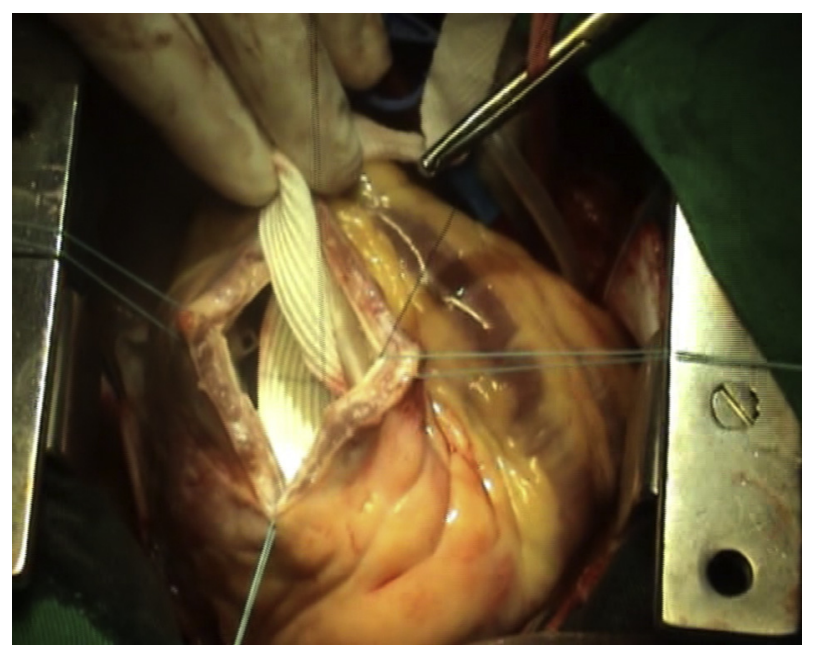

VIDEO 1. Surgical technique of surgical ventricular restoration in a patient with ischemic cardiomyopathy and refractory heart failure using a rectangular intra ventricular patch. Video available at: https://www.jtcvs. org/article/S2666-2736(21)00051-6/fulltext. postoperative period, a systolic volume $<60 \mathrm{~mL} / \mathrm{m}^{2}$ had a significantly lower 5-year mortality than patients where the systolic volume was $\geq 60 \mathrm{~mL} / \mathrm{m}^{2}(9.8 \%$ vs $27.0 \%)$. Patients with postoperative volume reduction $\geq 30 \%$, if compared with patients with volume reduction $<30 \%$, had a lower 5year mortality ( $13.5 \%$ vs $22.1 \%$ ). The 5 -year mortality in CABG alone was $28 \%$, even if not directly comparable to the previous data. ${ }^{15}$ These findings imply that a further analysis of the STICH trial found that, with a correct surgical technique and a good surgical indication, survival of patients who had CABG and SVR was definitively high and very likely better than survival of patients who had CABG alone.

Therefore, extrapolating our findings of 2 years of medical treatment alone, we can hypothesize preserved RWT may benefit from SVR. SVR in reduced RWT may not have good outcomes because it may resurrect the Batista debacle. ${ }^{16,17}$

\section{Limitations}

This is a small sample size pilot study with a short followup period of 24 months. Longer follow-up may be required to determine factors affecting mortality. We also could not do the Cox proportional hazard model for mortality because the mortality numbers were too low. The lack of cardiac magnetic resonance data is also a limitation in investigating the relationship between RFP, RWT, ischemia, and replacement fibrosis. Another major limitation of our study is that we have studied the association of RWT on outcomes of heart failure in medically treated patients. We did not study patients who underwent SVR. The association of RWT on outcomes in patients who underwent SVR will be our next objective. 


\section{LEFT VENTRICULAR FUNCTION AND SURVIVAL IN ISCHEMIC CARDIOMYOPATHY}

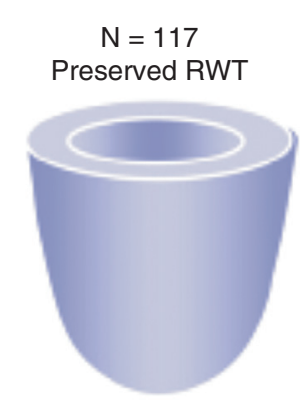

Patients with preserved RWT had significantly lower

all cause mortality and re-admission rates for heart failure.

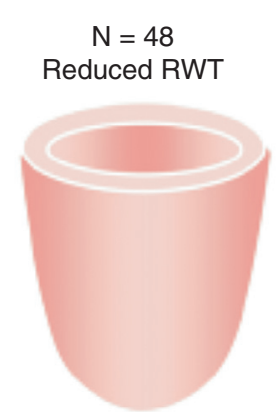

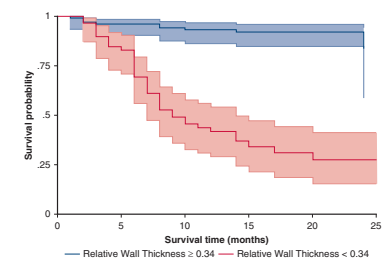

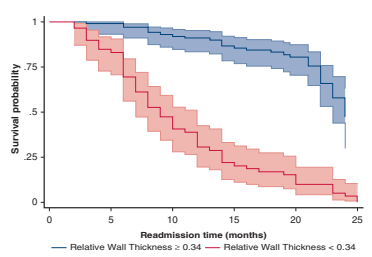

RWT: Relative Wall Thickness

FIGURE 4. Left ventricular function and survival in ischemic cardiomyopathy. Patients with preserved relative wall thickness (RWT) had lesser all-cause mortality and readmissions for heart failure.

\section{CONCLUSIONS}

In this pilot study, patients with ICM who showed a preserved RWT indicative of eccentric LV remodeling were associated with decreased mortality (Figure 4). As was seen in previous studies, it can be hypothesized that the eccentric remodeling pattern in ICM may be a better substrate for SVR.

\section{Conflict of Interest Statement}

The authors reported no conflicts of interest.

The Journal policy requires editors and reviewers to disclose conflicts of interest and to decline handling or reviewing manuscripts for which they may have a conflict of interest. The editors and reviewers of this article have no conflicts of interest.

\section{References}

1. Jones RH, Velazquez EJ, Michler RE, Sopko G, Oh JK, O’Connor CM, et al. Coronary bypass surgery with or without surgical ventricular reconstruction. $N$ Engl J Med. 2009;360:1705-17.

2. Buckberg GD, Athenasuleas C. The STICH trial: misguided conclusions. J Thorac Cardiovasc Surg. 2009;138:1060-4.

3. Athanasuleas CL, Buckberg GD, Stanley AW, Siler W, Dor V, Di Donato M, et al. Surgical ventricular restoration in the treatment of congestive heart failure due to post-infarction ventricular dilation. J Am Coll Cardiol. 2004;44:1439-45.

4. Dini FL, Capozza P, Donati F, Simioniuc A, Corciu AI, Fontanive P, et al. Patterns of left ventricular remodeling in chronic heart failure: prevalence and prognostic implications. Am Heart J. 2011;161:1088-95.

5. Lester SJ, Tajik AJ, Nishimura RA, Oh JK, Khandheria BK, Seward JB. Unlocking the mysteries of diastolic function. Deciphering the Rosetta Stone 10 years later. J Am Coll Cardiol. 2008;51:679-89.

6. Meta-analysis Research Group in Echocardiography (MeRGE) Heart Failure Collaborators, Doughty RN, Klein AL, Poppe KK, Gamble GD, Dini FL, et al. Independence of restrictive filling pattern and LV ejection fraction with mortality in heart failure. Eur J Heart Fail. 2008;10:786-92.
7. Fantini F, Toso A, Menicanti L, Moroni F, Castelvecchio S. Restrictive filling pattern in ischemic cardiomyopathy: insights after surgical ventricular restoration. J Thorac Cardiovasc Surg. 2021;161:651-60.

8. Nagueh SF, Smiseth OA, Appleton CP, Byrd BF III, Dokainish H, Edvardsen T, et al; ASE/EACVI Guidelines and Standards. Recommendations for the Evaluation of left ventricular diastolic function by echocardiography: an update from the American Society of Echocardiography and the European Association of Cardiovascular Imaging. J Am Soc Echocardiogr. 2016;29:277-314.

9. Lang RM, Bierig M, Devereux RB, Flachskampf FA, Foster E, Pellikka PA, et al. Recommendations for chamber quantification: a report from the American Society of Echocardiography's guidelines and standards committee and the chamber quantification writing group, developed in conjunction with the European Association of Echocardiography, a branch of the European Society of Cardiology. $J$ Am Soc Echocardiogr. 2005;18:1440-63.

10. Feldman AM, Mann DL, She L, Bristow MR, Maisel AS, McNamara DM, et al Prognostic significance of biomarkers in predicting outcome in patients with coronary artery disease and left ventricular dysfunction. Circ Heart Fail. 2013;6: 461-72.

11. Castelvecchio S, Baryshnikova E, Pina IL, Ambrogi F, Milani V, Tramarin R et al. Longitudinal profile of NT-proBNP levels in ischemic heart failure patients undergoing surgical ventricular reconstruction: the Biomarker Plus study. Int $J$ Cardiol. 2018;260:24-30.

12. Pocar M, Di Mauro A, Passolunghi D, Moneta A, Alsheraei AM, Bregasi A, et al Predictors of adverse events after surgical ventricular restoration for advanced is chaemic cardiomyopathy. Eur J Cardiothorac Surg. 2010;37:1093-103.

13. Di Donato M, Sabatier M, Dor V, Toso A, Maioli M, Fantini F. Akinetic versus dyskinetic postinfarction scar: relation to surgical outcome in patients undergoing endoventricular circular patch plasty repair. J Am Coll Cardiol. 1997;29: 1569-75.

14. Holly TA, Bonow RO, Arnold JM, Oh JK, Varadarajan P, Pohost GM, et al Myocardial viability and impact of surgical ventricular reconstruction on outcomes of patients with severe left ventricular dysfunction undergoing coronary artery bypass surgery: results of the Surgical Treatment for Ischemic Heart Failure trial. J Thorac Cardiovasc Surg. 2014;148:2677-84.

15. Michler RE, Rouleau JL, Al-Khalidi HR, Bonow RO, Pellikka PA, Pohost GM, et al. Insights from the STICH trial: change in left ventricular size after coronary artery bypass grafting with and without surgical ventricular reconstruction. $J$ Thorac Cardiovasc Surg. 2013;146:1139-45.

16. Konstam MA, Kramer DG, Patel AR, Maron MS, Udelson JE. Left ventricular remodeling in heart failure: current concepts in clinical significance and assessment. JACC Cardiovasc Imaging. 2011;4:98-108.

17. Schinkel AF, Poldermans D, Rizzello V, Vanoverschelde JL, Elhendy A, Boersma E, et al. Why do patients with ischemic cardiomyopathy and a 
substantial amount of viable myocardium not always recover in function after revascularization? J Thorac Cardiovasc Surg. 2004;127:385-90.
Key Words: left ventricle, relative wall thickness, surgical ventricular restoration, heart failure 